\title{
Chapter
}

\section{Analyzing protein clusters on the plasma membrane: application of spatial statistical analyses on super-resolution microscopy images}

\author{
Laura Paparelli, Nikky Corthout, Benjamin Pavie, Wim Annaert, Sebastian Munck
}

\begin{abstract}
The spatial distribution of a protein within the cell affects its capability to interact with other molecules and directly influences cellular processes and signaling. At the plasma membrane, multiple factors drive protein compartmentalization into specialized functional domains leading to the formation of clusters in which inter-molecule interactions are facilitated. Therefore, quantifying protein distributions is a necessity for understanding their regulation and function. The recent advent of superresolution microscopy has opened up the possibility of imaging protein distributions at the single molecule level with nanometer precision. In parallel, new spatial analysis methods have been developed to quantify distribution patterns in super-resolution images. In this chapter, we provide an overview of super-resolution microscopy and summarize the factors influencing protein arrangements on the plasma membrane. Finally, we highlight methods for analyzing clusterization of plasma membrane proteins, including examples of their applications.
\end{abstract}

Laura Paparelli ${ }^{\mathrm{a}, \mathrm{b}, \mathrm{c}}$, Nikky Corthout ${ }^{\mathrm{a}, \mathrm{c}, \mathrm{d}}$, Benjamin Pavie $^{\mathrm{a}, \mathrm{c}}$, Wim Annaert ${ }^{\mathrm{b}, \mathrm{c}}$, Sebastian Munck ${ }^{\mathrm{a}, \mathrm{c}, \mathrm{d}}$ (sebastian.munck@cme.vib-kuleuven.be)

${ }^{a}$ VIB Bio Imaging Core, Herestraat 49, Box 602, 3000 Leuven, Belgium.

${ }^{\mathrm{b}}$ Laboratory of Membrane Trafficking; Department of Human Genetics KU Leuven, Herestraat 49, Box 602, 3000 Leuven, Belgium.

${ }^{\mathrm{c}}$ VIB Center for the Biology of Disease, KU Leuven, Herestraat 49, Box 602, 3000 Leuven, Belgium.

${ }^{\mathrm{d}}$ LiMoNe, Department of Human Genetics KU Leuven Herestraat 49, Box 602, 3000 Leuven, Belgium. 


\section{Introduction}

In the last decades, several technological breakthroughs have been published that allow retrieving information from beyond the diffraction limit (Schermelleh et al., 2010; Klein et al., 2014) (see Box 1). These super-resolution techniques offer the possibility to observe the organization of structures in biological samples on the nanometer scale, providing novel insights on cell organization and cellular signaling (Sauer, 2013; Deschout et al., 2014). For cellular signal transduction the distribution of proteins on the plasma membrane plays a crucial role. To efficiently exploit their function, plasma membrane proteins often organize in clusters. Their spatio-temporal localization on the plasma membrane is, in fact, one of the elements regulating their interactions (Simons and Toomre, 2000).

Even if super-resolution imaging enables the visualization of the organization of plasma membrane proteins at the single molecule scale, the high level of detailed information present in these images is often difficult to interpret. Quantitative approaches, optimized from spatial statistics, have therefore been employed to decipher if a protein distribution is organized in clusters or it is random. In this context, membrane biology, super-resolution microscopy and novel analysis schemes, lead to a positive feedback loop pushing the boundaries of science and contributed to the emerging field of BioImage Informatics (BII), which combines computational image analysis and life sciences. The developments in the fields mentioned are the major topic of discussion in this review.

Starting from an overview of the different super-resolution microscopy techniques, we next describe the factors affecting the distribution of plasma membrane proteins. Finally, we discuss the statistical techniques available for assessing clusterization, focusing on nearest neighbor distance, K-Ripley function and pair correlation approaches. In this context, we provide examples of applications to emphasize the transformative role of these techniques for quantitative biology, with particular regard to the neuronal and the immunological synapse, where protein distribution has provided novel insights into the biology of signaling within these systems.

\section{Super-resolved fluorescence microscopy}

The recent past has seen several super-resolution techniques emerging that allow to observe structures in the sample beyond the diffraction limit (Abbe, 1873; Rayleigh, 1903; Sparrow, 1916) (see Box 1). Among these are: near-field scanning optical microscopy (NSOM) (Betzig and Trautman, 1992; Betzig and Chichester, 1993), stimulated emission depletion (STED) (Hell and Wichmann, 1994; Hell and Kroug, 1995), structured illumination microscopy (SIM) (Heintzmann and Cremer, 1999; Gustafsson, 2000) and single molecule detection methods like photo-activated localization microscopy (PALM) (Betzig et al., 2006), fluorescence photoactivation localization microscopy FPALM (Hess et al., 2006) and stochastic optical reconstruction microscopy (STORM) (Rust et al., 2006) (see Table1). 
Table 1. Characteristics of super-resolution microscopy techniques

\begin{tabular}{clcccc}
\hline Technique & \multicolumn{1}{c}{ Principle } & $\begin{array}{c}\text { Lateral } \\
\text { resolution } \\
(\mathrm{nm})\end{array}$ & $\begin{array}{c}\text { Axial } \\
\text { resolution } \\
(\mathrm{nm})\end{array}$ & Required dyes & $\begin{array}{c}\text { Image } \\
\text { processing }\end{array}$ \\
\hline \multirow{2}{*}{ NSOM } & $\begin{array}{l}\text { The near-field light existing at } \\
\text { the surface of an object is } \\
\text { collected by an optical fiber } \\
\text { with nano-sized aperture }\end{array}$ & $20-120$ & $\sim 10$ & $\begin{array}{c}\text { Conventional } \\
\text { dyes }\end{array}$ & No \\
\hline
\end{tabular}

\begin{tabular}{|c|c|c|c|c|c|}
\hline STED & $\begin{array}{l}\text { A small excitation spot is } \\
\text { generated by the overlapping of } \\
\text { two beams one that excite the } \\
\text { sample, the other that depletes } \\
\text { the fluorescence at the } \\
\text { periphery of the excitation } \\
\text { beam }\end{array}$ & 50 & $\sim 80^{*}$ & $\begin{array}{c}\text { Conventional } \\
\text { dyes }\end{array}$ & No \\
\hline SIM & $\begin{array}{l}\text { The sample is excited with a } \\
\text { structured illumination pattern } \\
\text { to extract high spatial frequency } \\
\text { information to reconstruct the } \\
\text { super-resolved image }\end{array}$ & $100-130$ & $250-350$ & $\begin{array}{c}\text { Conventional } \\
\text { dyes }\end{array}$ & Yes \\
\hline $\begin{array}{c}\text { PALM } \\
\text { FPALM } \\
\text { STORM }\end{array}$ & $\begin{array}{l}\text { Stochastic excitation of a } \\
\text { portion of fluorophores in the } \\
\text { sample is used to resolve in time } \\
\text { their fluorescence emission. } \\
\text { The multiple images acquired } \\
\text { are then processed to } \\
\text { reconstruct a final super- } \\
\text { resolved image }\end{array}$ & $10-50$ & $20-50$ & $\begin{array}{l}\text { Photoactivatble } \\
\text { or photo- } \\
\text { convertible } \\
\text { dyes (PALM) } \\
\text { Synthetic dyes } \\
\text { (STORM) }\end{array}$ & Yes \\
\hline
\end{tabular}

$*$ Resolution achieved by commercial devices

NSOM (Betzig and Trautman, 1992; Betzig and Chichester, 1993) explores evanescent waves at the surface of an object that is scanned by a probe. The size of the aperture of the probe imposes the resolution, which is typically in the range of $20 \mathrm{~nm}$. STED (Hell and Wichmann, 1994; Hell and Kroug, 1995) uses the combination of excitation and stimulated emission of fluorophores to create an effective point spread function (PSF) (see Box 1) smaller than the diffraction limit. NSOM and STED share the ability to achieve super-resolution without processing the images after acquisition. Structured 
illumination microscopy is a super-resolution technique that uses an illumination pattern (Heintzmann and Cremer, 1999; Gustafsson, 2000) for achieving optical sectioning. The interference pattern (moiré fringes) generated by the interaction of the grid with the sample are used to back-calculate the structure of the sample, gaining spatial information that is otherwise not accessible. This approach can achieve a lateral resolution of about $100 \mathrm{~nm}$ (Figure 1c), which can be further enhanced by using saturated structured illumination microscopy (SSIM) (Heintzmann et al., 2002; Heintzmann, 2003) to $<50 \mathrm{~nm}$ (Gustafsson, 2005).

Single-molecule localization techniques are based on the localization of a molecule by determining the center of a single fluorescence emitting object. Once the single localizations are determined, they can be assembled in a single super-resolution image, as initially proposed by pointillism (Lidke et al., 2005). Since this calculation is possible only if the PSFs from different fluorophores are at a distance higher than the diffraction limit, diverse image acquisition approaches were proposed to avoid signal overlapping. These approaches rely on resolving fluorescent molecules in time by stochastically acquiring a subset of fluorophores in the sample and by repeating the acquisition several times. In photoactivated localization microscopy (PALM) (Betzig et al., 2006) and in fluorescence photoactivation localization microscopy (FPALM) (Hess et al., 2006) this is achieved by the use of photoactivatable or photoconvertable dyes, while in stochastic optical reconstruction microscopy (STORM) pairs of photoswitchable dyes (like Cy3-Cy5) are adopted (Rust et al., 2006) (Figure 1d). The advent of these techniques has helped to reach a resolution of $\sim 20 \mathrm{~nm}$. Improved versions of the mentioned techniques includes: PALM with independently running acquisition (PALMIRA) (Geisler et al., 2007), stroboscopic PALM (sPALM) (Flors et al., 2007), direct STORM (dSTORM) (Heilemann et al., 2008; Heilemann et al., 2009) and ground state depletion microscopy (GSDIM) (Fölling et al., 2008). Super-resolution has also been achieved by the use of other approaches like point accumulation for imaging in nanoscale topography (PAINT) (Sharonov and Hochstrasser, 2006), super-resolution optical fluctuation imaging (SOFI) (Dertinger et al., 2009), focal modulation microscopy with annular aperture (AFMM) (Gong et al., 2010), Bayesian analysis of the blinking and bleaching (3B analysis) (Cox et al., 2012), photobleaching microscopy with non-linear processing (PiMP) (Munck et al., 2012), nonnegative matrix factorisation with iterative restarts (iNMF)(Mandula et al., 2014) and nanometer accuracy by stochastic chemical reactions (NASCA) (Ristanović et al., 2015).

Overall these new approaches have greatly enhanced the quality and the quantity of information gained on the organization of the cell and its compartments, including the plasma membrane and its complex architecture. 


\section{Box 1. Microscope resolution}

The resolution of a microscope is its ability to discriminate the features of the observed sample. The optical resolution is limited because of the diffraction of the light. Light diffraction is a phenomenon occurring when light finds a physical barrier or has to pass through a hole with a size comparable to light wavelength; in these cases light waves are spread out behind the obstacle generating a diffraction pattern called Airy disk pattern, whose intensity distribution is called Point Spread Function (PSF) (see figure below). For describing the resolution of the microscope several definitions are used. The Rayleigh criterion (Rayleigh, 1903) states that two objects with overlapping diffraction patterns can be resolved if the maximum of the Airy disk (central diffraction disk) coincides with the first minimum of the other diffraction pattern. Sparrow (Sparrow, 1916) used as definition the distance at which the PSFs of two objects are so close that their peaks exhibit constant brightness, therefore cannot be discerned. Both measures are based on the PSF and consequently the full width at half maximum of the PSF is used as a resolution measure. Apart from these straightforward measures Ernst Abbe (Abbe, 1873) described the resolution limit as a fundamental diffraction barrier. Abbe used the cutoff frequency of the optical transfer function as the limit of diffraction. This would, in the real world, correspond to the frequency of a grid of objects, which cannot be resolved and will be imaged as a homogenous plane of intensity. It is of note that practically image resolution is limited by noise and other distortions as well. Therefore, in accordance to earlier work on electron microscopy images, a practical measure for the resolution in super-resolution images based on the image was proposed recently (Nieuwenhuizen et al., 2013); this measure is based on Fourier ring correlation.
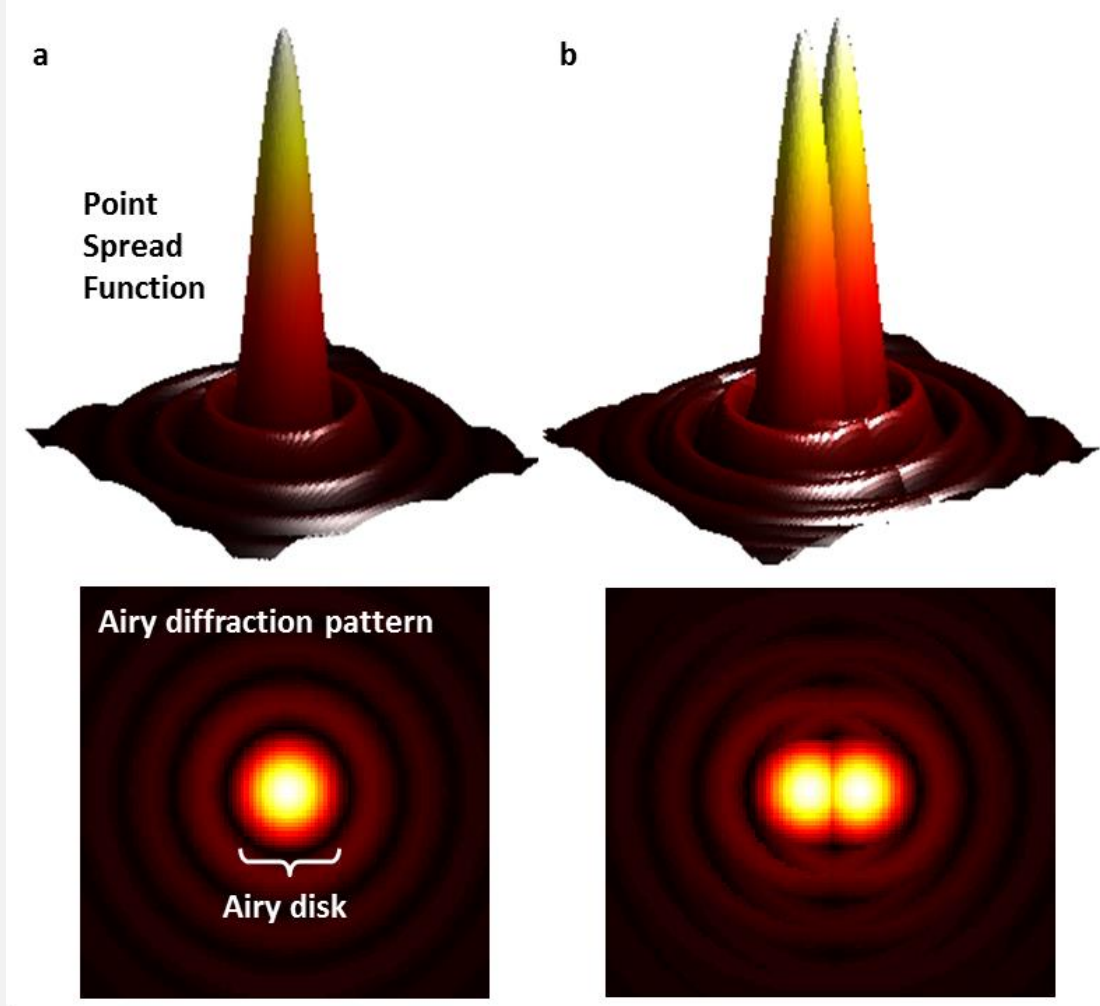

Sketch of the Point Spread Function a Representation of the Point Spread Function (PSF) (top image) and the Airy pattern (bottom figure) generated by a single source of light. b Overlapping PSFs and airy patterns generated by two different sources of light. 

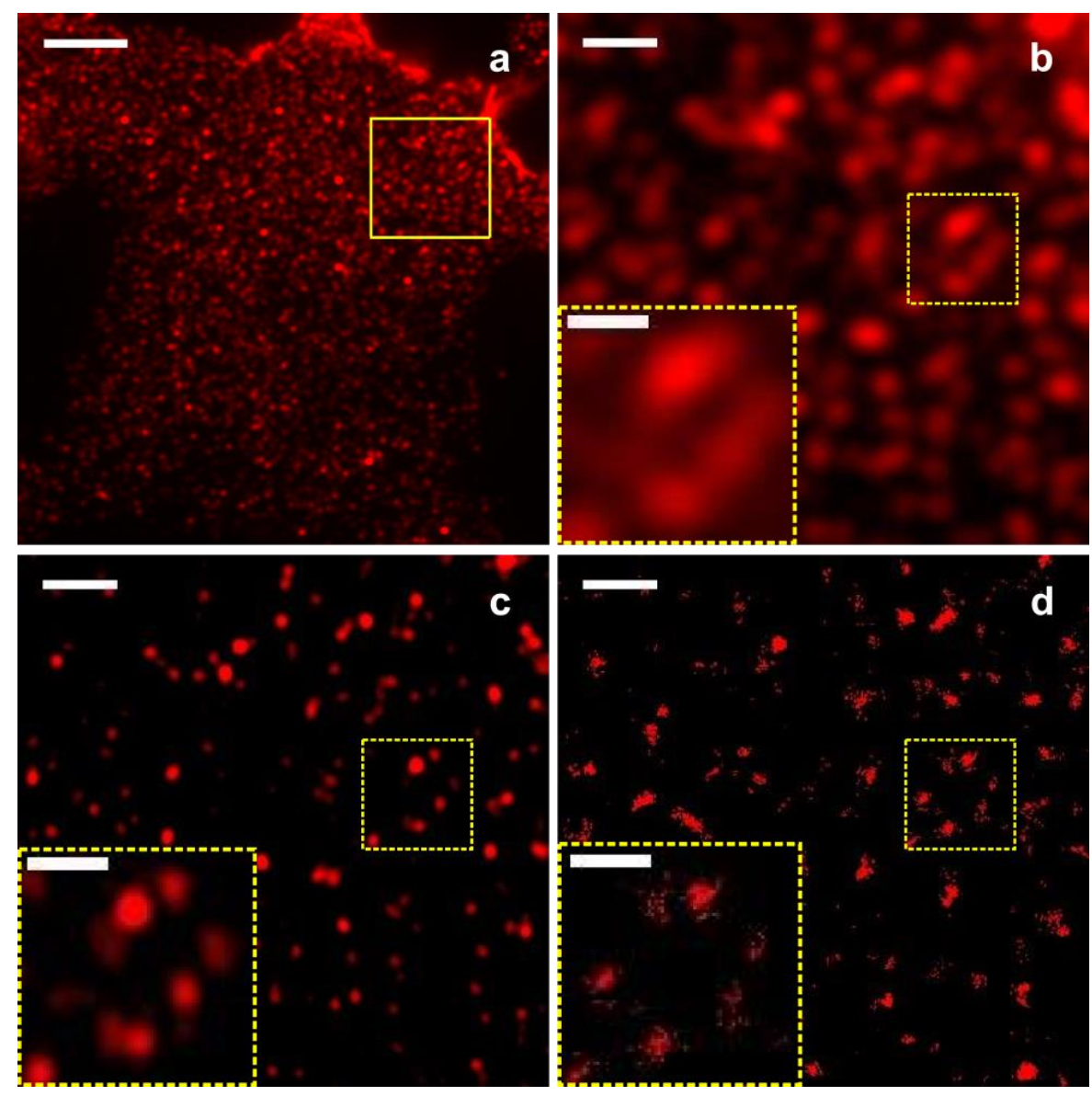

Fig. 1. Immunolocalization of $\mathrm{Na}^{+} / \mathrm{K}^{+}$ATPase on isolated plasma membrane (Chaney and Jacobson, 1983) as acquired by different types of microscopy techniques (Hamel et al., 2014). a Widefield microscopy (scale bar: $5 \mu \mathrm{m}$ ), b-d Zoom of the selected region in figure (a) as imaged by widefield (b), SIM (c) and dSTORM (d) including a detailed area. Scale bars: b, c, d: $1 \mu \mathrm{m}$. Scale bars of the inserts in $\mathbf{b}, \mathbf{c}, \mathbf{d}: 0.5 \mu \mathrm{m}$.

The sample was stained for $\mathrm{Na}^{+} / \mathrm{K}^{+}$ATPase using standard immunochemistry procedures with a mouse monoclonal primary antibody (\#NB300-146, Novus Biologicals) followed by the secondary antibody staining with goat anti mouse alexa fluor 647 (A-21241, Invitrogen, polyclonal). Widefield and SIM images were acquired on an inverted Zeiss Elyra S.1 microscope using a PlanAPOCHROMAT 63X 1.4 oil objective lens. dSTORM images were acquired using a breadboard setup as described before (Adam et al., 2011; Munck et al., 2012). dSTORM images were reconstructed using QuickPALM (Henriques et al., 2010). The widefield, SIM and dSTORM images were aligned using TrakEM2 (Cardona et al., 2012).

\section{Overview on plasma membrane architecture}

The essential structure of cellular membranes is a lipid bilayer (Gorter and Grendel, 1925) in which proteins are embedded. Even though early thermodynamic studies suggested the free lateral diffusion of membrane proteins in this bilayer (leading to the proposition of the fluid-mosaic model (Singer and Nicolson, 1972)), our current perception of the plasma membrane organization has been integrated by novel discoveries suggesting the presence of constraints to protein movement (Nicolson, 2014; GarciaParajo et al., 2014). During the past decades, in fact, a more complex architecture of the plasma 
membrane has been revealed, demonstrating how the compartmentalization of proteins and lipids is directed by several factors and events.

\subsection{Lipid domains}

One of these factors is the existence of highly ordered lipid domains called lipid rafts (Simons and Van Meer, 1988; Simons and Ikonen, 1997). These are small (10-200 nm), dynamic domains enriched in cholesterol, sphingolipids and saturated phospholipids that interact with specific proteins to compartmentalize signaling processes (Pike, 2006; Simons and Sampaio, 2011). Model membranes and biophysical studies showed lipid raft to be in a liquid ordered state, where satured lipids and cholesterol are tightly packed together (as in a solid ordered phase) but show rapid lateral mobility (as in a liquid disorder state) (Ipsen et al., 1987; London, 2002). In the plasma membrane this state co-exists with the liquid disorder phase characteristic of the unsatured lipid-rich membrane surrounding lipid rafts (Feigenson, 2007; Veatch et al., 2007). These states regulate the activity of membrane proteins, like receptors, mediating the signaling output (Sezgin et al., 2015). Membrane trafficking (Diaz-Rohrer et al., 2014), cancer regulation (Mollinedo and Gajate, 2015), lymphocyte activation (Owen et al., 2010) and neuropathogenesis (Marin et al., 2013) are some of the processes known to be influenced by lipid rafts through the partition or exclusion of signaling proteins within these domains. Protein affinity to raft domains is often regulated by lipid modifications that allow anchoring the lipidated proteins to the membranes. Particularly, the interaction with lipid raft domains is facilitated by the addition of sterols and saturated fatty acids, for instance through palmitoylation (Levental et al., 2010). Alternatively, protein partition into lipid rafts occurs as well via glycophosphatidylinositol (GPI)-anchors (Brown and Rose, 1992; Schroeder et al., 1994).

A specialized type of cholesterol-rich domains is present at the cell surface in the form of omegashaped invaginations called caveolae. These small pits of the plasma membrane, $60-70 \mathrm{~nm}$ in diameter, were first observed through electron microscopy in the middle of the last century (Palade, 1953; Yamada, 1955). Caveolae present a characteristic coat (Peters et al., 1985) consisting of different proteins including caveolins (Rothberg et al., 1992; Scherer et al., 1995; Scherer et al., 1996; Tang et al., 1996), cavins (Liu et al., 2008; Hansen et al., 2009; McMahon et al., 2009; Bastiani et al., 2009) and the recently discovered components pacsin2 (Senju et al., 2011;Hansen et al., 2011) and EHD2 (Stoeber et al., 2012; Morén et al., 2012). The assembly of these components results in a tightly organized ultrastructure (Hayer et al., 2010; Ludwig et al., 2013; Gambin et al., 2014) that contributes to the spatial organization of signaling molecules (Parton and del Pozo, 2013). Caveolae form a 'sink' for molecules involved in cellular signaling restricting the environment in which they can function, as in the case of endothelial nitric oxide synthase (eNOS) (García-Cardeña et al., 1996; Ramadoss et al., 2013). In addition to other functions, such as cholesterol homeostasis, mechanosensing and cell proliferation (Parton and Simons, 2007; Nassoy and Lamaze, 2012), caveolae also play a role in internalization and transport of proteins (Pelkmans et al., 2004; Chaudhary et al., 2014). 


\subsection{Protein domains}

The organization of plasma membrane constituents is additionally directed by scaffolding proteins that promote the formation of other specialized domains. Testraspanins, for instance, are a large group of proteins (Boucheix and Rubinstein, 2001) characterized by four transmembrane domains (Wright and Tomlinson, 1994; Stipp et al., 2003; Seigneuret, 2006). The association of tetraspanins with other tetraspanins and their interaction with various transmembrane receptors (i.e. adhesion receptors, grow factors receptors, immunoglobulin-domain containing factors and cytokine receptors) leads to the formation of an extended network, which is at the base of tetraspanins-enriched microdomains (TEMs) (Hemler, 2003; Hemler, 2005). TEMs regulate the spatial distribution of the associated molecules by packing them in large clusters $(\sim 300 \mathrm{~nm})$ (Barreiro et al., 2008) that have roles in various cell functions spanning cell adhesion, motility, differentiation and protein trafficking (Yáñez-Mó et al., 2009). Flotillins are other scaffolding proteins known to form microdomains at the plasma membrane (Solis et al., 2007) through the interaction of the two homologues flotillin 1 and flotillin 2 (Schulte et al., 1997). These domains have been shown to act as platforms for signaling processes and endocytosis (Otto and Nichols, 2011; Meister and Tikkanen, 2014).

\subsection{Cytoskeleton}

Besides interactions among plasma membrane constituents, other cellular components like cytoskeletal proteins have an influence on the distribution of the plasma membrane proteins and lipids. In 1993, Kusumi et al. proposed the membrane skeleton fence model to explain the non-homogeneous distribution of plasma membrane proteins and their confined diffusion (Kusumi et al., 1993). According to this model, the lateral diffusion of integral plasma membrane proteins is regulated by the subcortical skeleton network, which represents a barrier ('fence') to the free diffusion of proteins due to steric interactions between cytoplasmatic domains of transmembrane proteins and the actin meshwork in proximity of the plasma membrane (Kusumi and Sako, 1996). This obstacle causes a transient confinement of the proteins in domains; the movement from one domain to another ('hop diffusion') is possible thanks to the fluctuation of the skeleton network position. Hop diffusion has also been associated to membrane lipids (Fujiwara et al., 2002; Ehrig et al., 2011) and is explained by the presence of transmembrane proteins anchored to the cytoskeleton that slow down lipid diffusion. This slower diffusion is due to hydrodynamic friction between the lipids and the immobilized proteins. These findings have led to the definition of a more complete model that explains the influence of the cytoskeleton on the organization of membrane constituents, the so-called 'picket-fence model' (Ritchie et al., 2003; Kusumi et al., 2011). 


\subsection{Other factors}

An extracellular mechanism for microdomain organization at the cell surface is represented by secreted glycan-binding proteins, such as galectins, that interact with specific glycan structures of plasma membrane glycoproteins and glycolipids. Galectins, like other glycan-binding proteins, are multivalent and therefore are able to cross-link different glycans promoting the formation of a lattice (Brewer et al., 2002). Galectin lattices direct glycoprotein clustering (Belardi et al., 2012) in specialized domains regulating the associated signaling events (Rabinovich et al., 2007; Garner and Baum, 2008; Boscher et al., 2011). In addition, the galectin lattice has also been shown to play a role in both clathrin-mediated (Torreno-Pina et al., 2014) and clathrin-independent endocytosis (Lakshminarayan et al., 2014).

These different levels of compartmentalization (Mueller et al., 2012) provide the plasma membrane with the ability to increase the frequency of specific interactions by spatio-temporal confinement of the signaling events (Saka et al., 2014). Beyond the compartmentalization of plasma membrane components, cellular polarity, which is the asymmetric organization of cellular organelles and plasma membrane constituents, imposes additional complexity to the plasma membrane of polarized cells (for details on cell polarity see review (Li and Gundersen, 2008)).

\section{Plasma membrane protein distribution analysis}

The strong relationship between the localization of plasma membrane proteins and cell signaling (Simons and Toomre, 2000; Kusumi et al., 2012) has stimulated the development of analytical tools to quantify protein localization and distribution. Determining the localization of proteins or lipids in subcellular compartments or membrane domains is possible by co-localization analysis. This analysis defines the localization of a protein by measuring the spatial overlap between its fluorescent signal and the signal of a marker for a certain cellular compartment or domain. A detailed description of colocalization analysis is given by Bolte and Cordelières (Bolte and Cordelières, 2006). Another type of technique for analyzing the organization of plasma membrane components is single molecule tracking of proteins at the cell surface (reviewed in (Kusumi et al., 2014)). This approach allows tracking the position of molecules in time giving valuable insights into protein behavior, dynamics and interactions. Beyond the information on proteins sub-cellular localization, which can be determined by colocalization analysis, and beyond protein movements that can be followed by molecules tracking, it is of increasing interest in biology to assess the organization of a protein on the cells surface. For instance, understanding whether a protein clusters or re-distributes is relevant to define its interactions with partner molecules and the spatio-temporal features of the events with which it is involved. To determine protein distribution patterns, spatial statistical methods are often employed. These approaches are the focus of the following description.

For analyzing the distribution pattern of plasma membrane proteins, the latter are often regarded as point processes in a bi-dimensional spaces. A point process can adopt various patterns (Baddeley, 2007) 
including a complete spatial randomness (CSR) in which points are uniformly distributed (Figure 2a), a distribution in clusters, where points tend to aggregate (Figure $2 b$ ) or a regular distribution, characterized by points more ordered than in the random distribution (Figure 2c). To determine the deviation from the CSR, in terms of clustering or regularity, various statistical approaches are possible (Baddeley, 2007). Here we will focus on the ones that explore the relationship between the points of the pattern by measuring the inter-point distances. These include nearest neighbors methods, the K-Ripley function and the pair correlation function (see Box 2). Nearest neighbor distances (Figure 2d) allow determining if a pattern is random, clusterized or regular based on the mean distance between the points of the process and their closest neighbor (Cressie, 1993). K-Ripley (Figure 2e) and pair correlation function (Figure $2 \mathrm{f}$ ) both measure the number of neighbors within a certain radius to a point to determine the amount of clusterization (Ripley, 1977; Cressie, 1993), with the difference that while the K-Ripley function considers all the points with in a circle, the pair-correlation function takes the points within a ring into account reducing the influence of points at short distance to the center on the distribution. These techniques permit, in addition to pattern recognition, the determination of cluster characteristics, such as size, and therefore are broadly used and optimized for protein distribution analysis (Lagache et al., 2013; Shivanandan et al., 2015).
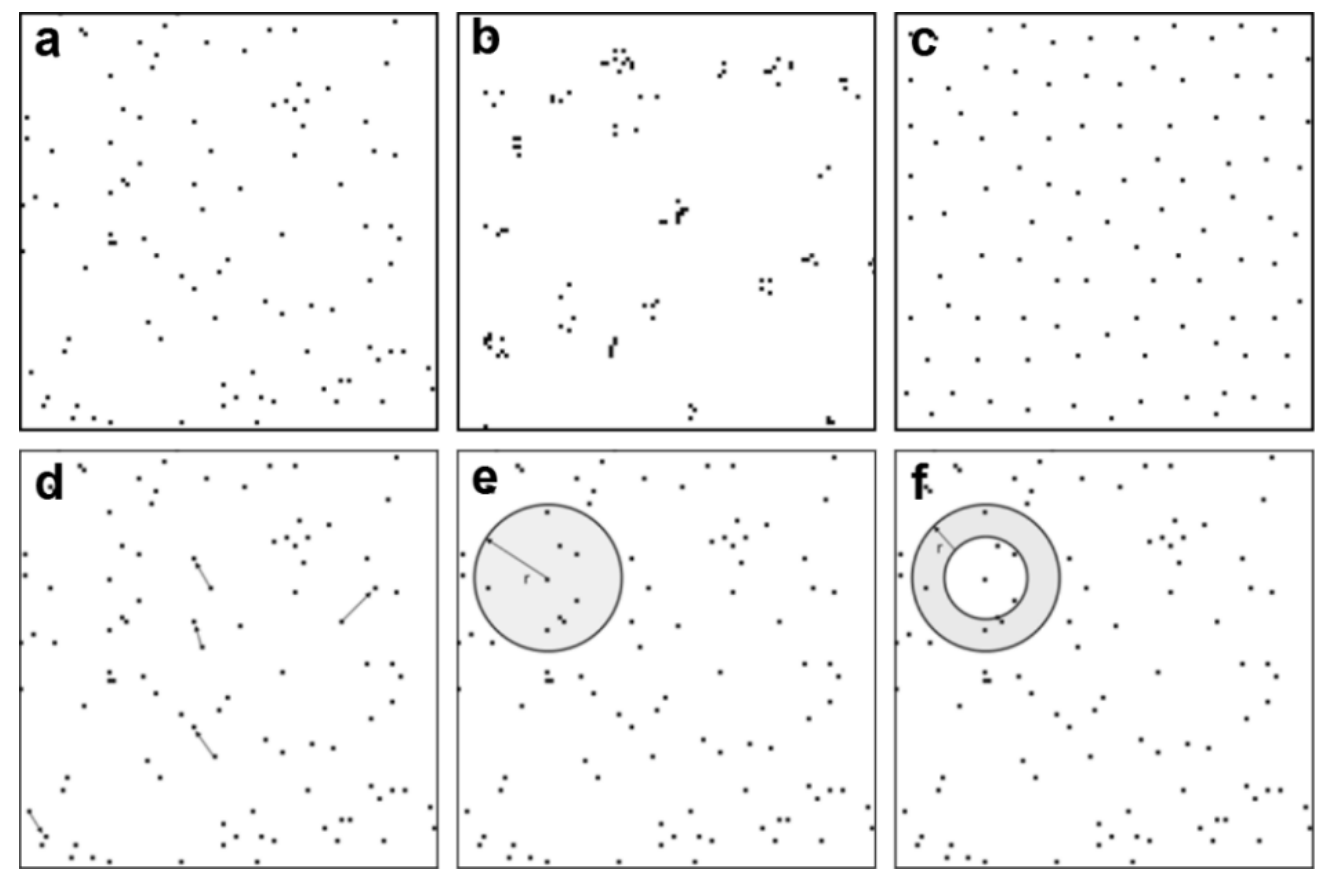

Fig. 2. Examples of spatial point patterns and statistical analysis. a Randomness, b Clustering, c Regularity, d Nearest neighbor approach, e K-Ripley function approach, f Pair correlation function approach. 


\section{Box 2. Point processes spatial statistical analysis}

A spatial point process $X \in A \subset \mathbb{R}^{2}$ represents the locations of an object of study (events) in the finite bi-dimensional space $A$. Spatial point processes are used as statistical model to determine which pattern the object of study follows over the area in which it is distributed (Wiegand and Moloney, 2013). To determine point clusterization three main techniques are described here:

\section{Nearest neighbor methods}

The distance between each point of the set and its closest neighbor is measured. The nearest neighbor average distance distribution $D(h)$ is then compared with the one expected for the random distribution to characterize clusterization and regularity.

$D(h)=\frac{N\left[\min _{i \neq j}\left(d_{i j}\right) \leq h\right]}{n}$ where $\min _{i \neq j}\left(d_{i j}\right)$, represents the minimum distance between two points, is at most $h$. $N$ represents the number of points at distance $d_{i j} \leq h$, and $n$ is the total number of points in the area of study (Diggle, 2003) (Prodanov et al., 2007) .

\section{K-Ripley function}

Differently than in the nearest neighbor methods, K-Ripley function analyzes the characteristics of the pattern at different distance scales. The number of points located within a certain radius $r$ from each point of the space is, in fact, calculated for increasing radii of the circle. The results are then compared to the ones typical for the complete spatial randomness to identify the degree of points clustering. Considering a circle of radius $r$, K-Ripley function can be estimated by:

$K(r)=\lambda^{-1} \sum_{i} \sum_{j \neq i} \frac{I\left(d_{i j}<r\right)}{N}$ where $\lambda$ is the density of the points in the studied region, $d_{i j}$ is the distance between the $i^{\text {th }}$ and the $j^{\text {th }}$ points, $I(x)$ is the indicator function with value one when $x$ is true and zero if $x$ is false and $N$ being the number of points in the area of study. Once Ripley's $\mathrm{K}$ function is estimated, the complete spatial randomness can be tested considering that for a point process exhibiting CSR, $K(r)=\pi r^{2}$ for all $r$. To have a constant value under CSR, a popular choice is to use the L-function: $L(r)=\sqrt{\frac{K(r)}{\pi}}$ for $r \geq 0$. The normalized form $H(r)=L(r)-r$ indicates CSR if it is equal to zero, while $H(r)>0$ indicates clustering and $H(r)<0$ indicates regularity (Dixon, 2002).

\section{Pair-correlation function}

Pair correlation function $G(r)$ can be related to the K-Ripley function $K(r)$ through: $G(r)=\frac{1}{2 \pi r} \frac{d K(r)}{d r}$ for $r \geq 0$ where $r$ is the circle radius.

In a complete CSR process $G(r)=1, g(r)>1$ implies a higher density of points around $r$ in comparison to the random process, while $G(r)<1$ suggest a regular pattern. One of the main differences is that the pair correlation function is less cumulative than the K-Ripley function (see Figure 2) (Mattfeldt, 2005). 


\subsection{Assessing plasma membrane protein clusterization by spatial statistics}

K-Ripley distribution analysis was initially employed in electron microscopy for investigating protein patterns within plasma membrane sheets (Zhang et al., 2006; Kiskowski et al., 2009). Using this approach, particular interest has been directed towards the analysis of the distribution of Ras proteins. In mammalian cells, these small GTPases exist in three different isoforms (H-, K- and N-Ras) which are organized in distinct non-overlapping nanoclusters due to a differential sensitivity to cholesterol and phosphatidylserine (Prior et al., 2003; Zhou et al., 2014) (reviewed in (Zhou and Hancock, 2015)). In addition, organization and signaling of Ras molecules were demonstrated to be altered by loss of caveolae (Ariotti et al., 2014), suggesting their involvement in lipid organization and signaling regulation.

In the context of protein compartmentalization and cell signaling, K-Ripley function has been applied on super-resolution images where it was used to identify the nature of clustering of the G-protein coupled receptor (GPCR) $\beta_{2}$-adrenergic receptor (Scarselli et al., 2012). This study demonstrated that cluster formation is not affected by cholesterol removal while actin polymerization inhibition leads to the reduction of cluster number, excluding $\beta_{2}$-adrenergic receptor enrichment in lipid raft domains. Arrestins are a family of proteins involved in signal transduction through GPCRs that also play a role in endocytosis of these and other receptors. Recently, a method to quantify arrestin2 clustering, occurring after GPCR stimulation, has been proposed (Truan et al., 2013). This approach employs dSTORM combined with nanobody labeling (Ries et al., 2012). Arrestin2 distribution analysis and cluster size evaluation was carried out by Ripley's function calculation in combination with image-based cluster analysis, which account for the fluorescence intensity. The increase of arrestin2 cluster size (initially larger than $100 \mathrm{~nm}$ ) upon blocking of actin polymerization, indicate a role for actin in the organization of arrestin at the cell surface.

An algorithm exploiting pair-correlation function has been developed to identify with high precision the localization of proteins in images acquired by PALM. This is called pair-correlation (PC)-PALM (recently reviewed in (Sengupta and Lippincott-Schwartz, 2012; Sengupta et al., 2013)), and allows the quantitative description of spatial protein organization. PC-PALM has probed the heterogeneity in the organization of plasma membrane proteins (Sengupta et al., 2011). This analysis revealed that GPIanchored proteins are aggregated in nano-clusters of smaller than $60 \mathrm{~nm}$, whose properties are sensitive to cholesterol and sphingomyelin levels as well as to the integrity of the actin cytoskeleton. The same strategy has also been used to demonstrate the alteration of GPI-anchored protein organization and actin polymerization upon cell treatment with pharmacologically relevant levels of ethanol (Tobin et al., 2014) and the distinct protein distribution of two splicing isoforms of the glycine receptor (Notelaers et al., 2014).

With regard to protein compartmentalization in tetraspanin domains, dSTORM imaging and spatial distribution analysis of tetraspanins and integrins have been used to investigate whether tetraspanin- 
directed arrangements of integrins can affect cell adhesion. Pair correlation function analysis, as developed by (Veatch et al., 2012) and applied on dSTORM images, has been used to determine the distribution of the tetraspanin CD82 and to assess the role of palmitoylation in CD82 clustering. In addition, density-based spatial clustering of application with noise (DBSCAN) (Ester et al., 1996), an algorithm that allows density-based detection of clusters, proved that integrin aggregation and density in clusters is modulated by CD82, allowing proper cell adhesion to the extracellular matrix (Termini et al., 2014).

In the context of membrane trafficking, the role of galactin-3 in the recruitment of cargos for clathrin independent endocytosis has been recently demonstrated (Lakshminarayan et al., 2014). In particular, galactin-3 has been shown to trigger the formation of clathrin-independent carriers (CLICs) upon interaction with glycoproteins containing $\mathrm{N}$-acetylglucosamine saccharides, such as CD44. In this case, dSTORM imaging and K-Ripley function analysis revealed that the aggregation of galectin-3 in small clusters $(75 \pm 2 \mathrm{~nm})$ at the cell surface is glycosphingolipids-dependent and that the N-glycosylation on CD44 is necessary for clustering and uptake. In addition, the relationship between host cell actin and the glycoprotein influenza viral membrane protein hemagglutinin was studied by FPALM and pair correlation function demonstrating the localization of the hemaglutinin in actin-rich membrane domains (Gudheti et al., 2013). Furthermore, blinking microscopy was used to investigate the relationship between these clusters and C-type lectin underlining their role in virus binding (Itano et al., 2012). In addition other ways of describing cluster sizes have been applied including Gaussian fits to individual clusters (Lehmann et al., 2011).

Protein spatial distribution analysis has also improved the characterization of events occurring in the specialized plasma membrane structures present in neuronal and immunological synapses where signal transmission takes place through a series of events highly coordinated in time and space.

\subsubsection{The neuronal synapse}

Neuronal synapses are specialized junctions $(10-20 \mathrm{~nm})$ that allow the transmission of chemical signals between neurons or between neurons and non-neuronal cells, for instance muscle cells. In the central nervous system, inter-neuronal chemical synapses are characterized by the presence of specialized zones in both presynaptic and postsynaptic neurons (Figure 3a). The specialized presynaptic element is called active zone and comprises a multitude of proteins involved in the exocytosis of synaptic vesicles (Südhof, 2012). The postsynaptic element is referred to as postsynaptic density (PSD) which consists of membrane and cytoplasmic proteins, including neurotransmitter receptors, scaffolding proteins and adhesion molecules involved in synaptic signal transduction and cell adhesion (Okabe, 2007).

At the presynaptic active zone, particular interest has been directed to the organization of SNARE (soluble $N$-ethylmaleimide-sensitive factor attachment receptor) proteins implicated in synaptic vesicle fusion and neuronal exocytosis such as syntaxin 1 and SNAP-25 (25 kDa synaptosome-associated 
protein) (Milovanovic and Jahn, 2015). STED microscopy in combination with fluorescence recovery after photobleaching (FRAP) has shown that syntaxin-1 exists both as clusters of 50-60 nm and free diffusing single molecules (Sieber et al., 2007). The organization of syntaxin within the clusters and the distribution of the single-molecules outside clusters was subsequently elucidated by dSTORM and clusters analysis (Bar-On et al., 2012). These investigations demonstrated a non-uniform distribution of syntaxin within the clusters, where protein density decreases toward the periphery of the clusters compared to the center, and a limited diffusion of the single-molecules. Cross-species pair correlation function, applied on two-color super-resolution images, gave detailed information on the assembly of a complex constituted by syntaxin-1, SNAP-25, and Secretory 1 (Sec1)/mammalian uncoordinated-18 (Munc18)-like protein (Pertsinidis et al., 2013). These complexes appear to be preassembled in $\leq 100$ $\mathrm{nm}$ microdomains at the plasma membrane of primary neurons. In parallel, the influence of phosphatidylinositol 4, 5-bisphosphate $\left(\mathrm{PI}(4,5) \mathrm{P}_{2}\right)$ (a phospholipid mainly present in the plasma membrane cytoplasmic leaflet) on SNARE protein clustering has been investigated to further elucidate SNARE-dependent membrane fusion and exocytosis (James et al., 2008). Confocal microscopy in combination with colocalization analysis has revealed that fusion events driven by syntaxin occur at the level of $\mathrm{PI}(4,5) \mathrm{P}_{2}$ clusters (Aoyagi et al., 2005). Here electrostatic protein-lipid interactions steer the organization of these microdomains (van den Bogaart et al., 2011) that have been proposed to act as molecular beacons for vesicle recruitment (Honigmann et al., 2013). In addition, it has been shown through PiMP imaging and colocalization analysis that also $\mathrm{PI}(3,4,5) \mathrm{P}_{2}$ facilitates syntaxin $1 \mathrm{~A}$ clustering at the presynaptic membrane, again through electrostatic interactions (Khuong et al., 2013).

The arrangement of postsynaptic neurotransmitter receptors, ion channels and scaffolding proteins are of particular interest given that synapse function can be affected by PSD architecture. One of the first quantitative measurements of receptor organization on super-resolution microscopy images was the arrangement of nicotinic acetylcholine receptors. This receptor, imaged by STED microscopy and analyzed by K-Ripley function (Kellner et al., 2007), has been found to be organized in nanoclusters, whose size is cholesterol-dependent. Spatial distribution of the sodium potassium pump $\left(\mathrm{Na}^{+} / \mathrm{K}^{+}\right.$ ATPase) and dopamine D1 receptor was investigated by nearest neighbor analysis on STED images. Quantification of their spatial relationship revealed joint and separated confinement of D1 receptors and $\mathrm{Na}^{+} / \mathrm{K}^{+}$ATPase pumps, providing novel insights into the modulation of synaptic transmission (Blom et al., 2012). Combination of super-resolution microscopy techniques and electron microscopy have shed light on the AMPA receptor arrangement at the PSD (Nair et al., 2013). It was shown that the AMPA receptor has a nano-organization in clusters of $\sim 70 \mathrm{~nm}$ (containing $\sim 20$ receptors) that is dynamic in time and space and is regulated by the scaffolding protein PSD95 (Nair et al., 2013). In this regard, pair correlation-based analysis of live-cell PALM images has been adopted to map the spatial distribution of glutamate receptors and PSD95 within single PSDs (MacGillavry et al., 2013). The results from these studies indicate that AMPA receptors cluster within the PSD by distributing preferentially at the site of PSD95 domains. This heterogeneous distribution enables the shaping of postsynaptic responses. 
Additionally, high density single molecule tracking has been adopted for understand AMPA receptor molecular interactions (Hoze et al., 2012) and motility in relation to its conformational state (Constals et al., 2015).

\subsubsection{The immunological synapse}

The immunological synapse is an ordered and dynamic interface between two cells of the immune system (Xie et al., 2013). For instance, an immunological synapse is established between T-cells and antigen presenting cells (APCs). At this interface, proteins with various roles like receptors, signaling molecules and scaffolds trigger multiple events that finally lead to an immune response (Figure $3 \mathrm{~b}$ ). We refer to appropriate reviews for the details on the process of T-cell activation and signal transduction (Smith-Garvin et al., 2009; Malissen et al., 2014). Briefly, the activation of T-cells begins with the interaction between the T-cell receptor (TCR) and the peptide exposed by the major histocompatibility complex (MHC) class I or class II, located on the surface of the APC. The TCR form a multisubunit complex with the Cluster of Differentiation 3 (CD3) that contains the dimers $\mathrm{CD} \varepsilon \gamma, \mathrm{CD} \varepsilon \delta$ and $\mathrm{CD} \xi \xi$, whose cytoplasmic regions present the immunoreceptor tyrosine-based activation motifs (ITAMs). The binding between the TCR and the MHC induces the phosphorylation of ITAMs by Src protein tyrosine kinases including the lymphocytic-specific protein kinase (Lck). Phosphorylation of ITAMs allows the recruitment and activation of the zeta chain-associated protein kinase of $70 \mathrm{kDa}$ (ZAP-70), and the subsequent phosphorylation of the linker for activation of T-cells (LAT). LAT functions as a platform for the signaling proteins involved in the next steps of the signaling cascade. The signal propagation induced by LAT activation results in cytokine secretion.

Given the high coordination and organization of the proteins involved in T-cell activation, it is critically important to assess their spatial arrangement for a better comprehension of the mechanisms leading to the immunological response (Rossy et al., 2012). For this purpose, super-resolution microscopy techniques and spatial statistical analysis have been used to bring new insights into the nanoscale spatio-temporal organization of the immunological synapse. Because of the importance of LAT recruitment and activation, different studies focused on the analysis of its localization. Initially, the organization of TCR in relation with the distribution of LAT has been investigated by employing KRipley function analysis applied on both high speed PALM and transmission electron microscopy (TEM) (Lillemeier et al., 2010). From the application of these techniques, in combination with fluorescence cross-correlation spectroscopy, the presence of pre-clustered TCR and LAT on quiescent T-cells was demonstrated. According to this work, the domains in which TCR and LAT are concentrated (here called protein islands having a width of 100-220 nm) are separated, and after T-cell activation they concatenate with each other but they do not merge. Two-color PALM and pair correlation analysis were adopted to further study TCR clustering and its interaction with other signaling proteins including LAT and ZAP70 (Sherman et al., 2011). Differently from previous observations, this analysis showed that TCR and LAT nanoclusters are mixed in resting T-cells while less mixing is observed upon cell 
stimulation. When investigating LAT clusters employing K-Ripley function on PALM and dSTORM images (Williamson et al., 2011), the pre-existing LAT domains present in the resting cells were shown not to be phosphorylated neither recruited by the TCR. LAT molecules were instead recruited from subcellular vesicles and phosphorylated. This is however contradictory to another study -alternatively using chimeric CD4-LAT, which demonstrated that surface localized LAT was phosphorylated (Balagopalan et al., 2013). The differences in the results obtained by these different studies could be related to the different experimental conditions and timeframe of observed events. Nevertheless the employment of a variety of microscopy techniques and distribution analysis underlines the effort and the importance of protein organization assessment.
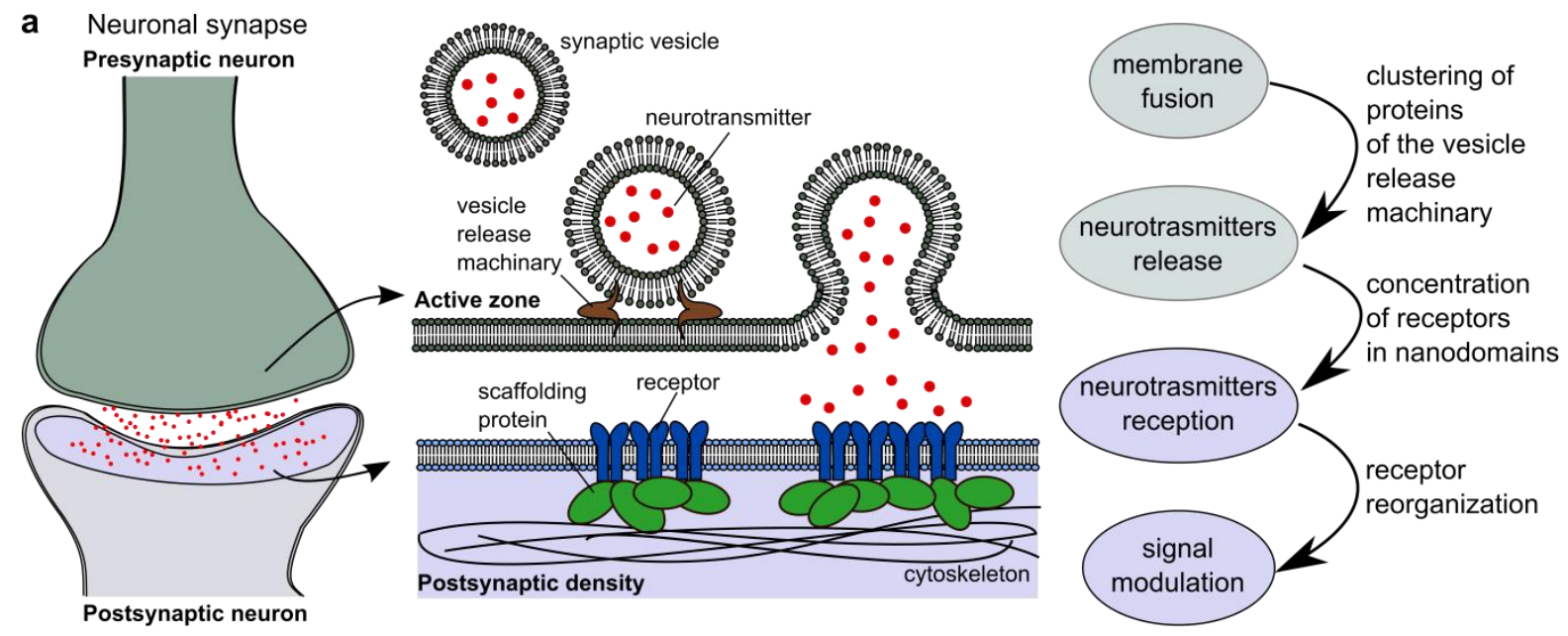

b Immunological synapse
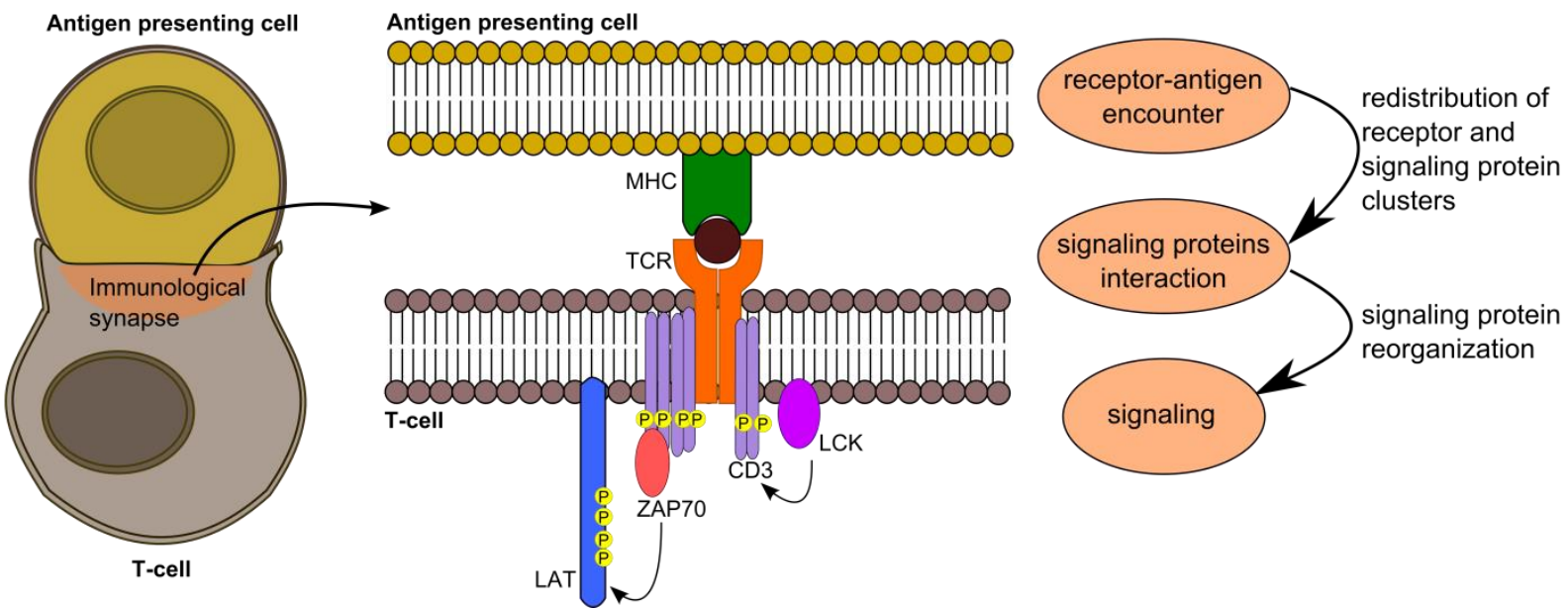

Fig. 3. Schematic of specialized plasma membrane structures: the neuronal and the immunological synapse. a Neuronal synapse. Neurotransmitter release occurs at the active zone of the presynaptic neuron; vesicle release is mediated by a SNAREs complexes. At the postsynaptic density, neurotransmitter receptors, like AMPA receptor, and scaffolding proteins, like PSD95, organize in domains to facilitate neurotransmission. b Immunological synapse (image adapted from (Friedl et al., 2005)). Upon antigen recognition by TCR, CD3 is phosphorylated by the kinase LCK. This leads to ZAP70 recruitment, which phosphorylates the adaptor LAT. 


\section{Conclusions and outlook}

The importance of quantitative measurements in biology together with the high-level development in microscopy technologies has favored the dawn of novel analyses paradigms aimed at protein pattern characterization, which is also explicated in the availability of the described tools for their use on image processing packaging like ImageJ/Fiji (Schindelin et al., 2012). PC-PALM analysis plugins are available in the package 'GDSC-SMLM' provided by the University of Sussex (http://sites.imagej.net/GDSC-

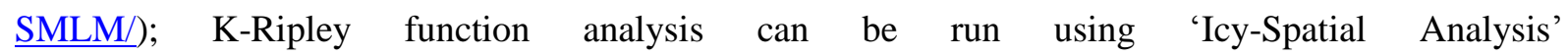
(http://icy.bioimageanalysis.org/plugin/Spatial_Analysis) other distribution analysis tools can be found in the 'BioVoxxel Toolbox' (http://fiji.sc/BioVoxxel Toolbox). Despite still being an emerging field, protein distribution analysis has already provided valuable insights into the mechanisms of protein compartmentalization at the plasma membrane. The improved understanding of these mechanisms has in turn enabled a better understanding of initiation and transduction of signaling processes. Concurrently with spatial distribution analysis, other analytical methods have supported investigations toward protein organization, including oligomerization analysis (Godin et al., 2011) and protein interaction analysis (Helmuth et al., 2010; Shivanandan et al., 2013). Together these techniques allow us to gradually build a detailed picture of protein arrangement in the plasma membrane starting from the oligomerization state of proteins, to the organization in clusters, leading to the definition of their interacting partners. While the picture that has emerged is complex, it is far from complete. Valuable information could be obtained from a more global analysis of the plasma membrane combined with the local investigation of clusters properties. As in other disciplines, like histopathology (Nawaz et al., 2015) and epidemiology (Haque et al., 2014), hotspot analysis through Getis-Ord G-statistics (Burt et al., 2009; Getis and Ord, 1992) could be employed. In the context of analyzing protein distributions on the plasma membrane one could think of multiplexing several readouts like calcium imaging and spatial analysis. The signaling readout could then be used as an additional weight for the distances of active receptors to determine the localization of hot spots for signaling initiation on the cell surface, and thus mapping the cell surface based on its functionality. In the future, it will be useful to pay attention to the complexity of the membrane and to integrate different readouts and analysis paradigms to create a more complete description of the processes and arrangements on the plasma membrane.

\section{Acknowledgements}

The authors would like to thank Dr. Susana Rocha and Dr. Vinoy Vijayan for fruitful discussion and Dr. Donna Stolz for the silica particles to isolate plasma membranes. This work is financially supported by VIB, VIB Bio Imaging Core facility, the Hercules foundation for heavy infrastructure (Hercules AKUL058/HER/08/021, AKUL/09/037 and AKUL13/39 (ISPAMM)), KU Leuven (IDO/12/020), the federal government (IAP P7/16) and SAO-FRA (S\#14017). SM was supported by a grant from KU Leuven (CREA/12/22). 


\section{References}

Abbe, E. (1873). Beiträge zur Theorie des Mikroskops und der mikroskopischen Wahrnehmung. Arch. Für Mikrosk. Anat. 9, 413-418.

Adam, V., Moeyaert, B., David, C.C., Mizuno, H., Lelimousin, M., Dedecker, P., Ando, R., Miyawaki, A., Michiels, J., Engelborghs, Y., et al. (2011). Rational design of photoconvertible and biphotochromic fluorescent proteins for advanced microscopy applications. Chem. Biol. 18, 1241-1251.

Aoyagi, K., Sugaya, T., Umeda, M., Yamamoto, S., Terakawa, S., and Takahashi, M. (2005). The activation of exocytotic sites by the formation of phosphatidylinositol 4,5-bisphosphate microdomains at syntaxin clusters. J. Biol. Chem. 280, 17346-17352.

Ariotti, N., Fernández-Rojo, M.A., Zhou, Y., Hill, M.M., Rodkey, T.L., Inder, K.L., Tanner, L.B., Wenk, M.R., Hancock, J.F., and Parton, R.G. (2014). Caveolae regulate the nanoscale organization of the plasma membrane to remotely control Ras signaling. J. Cell Biol. 204, 777-792.

Baddeley, A. (2007). Spatial Point Processes and their Applications. In Stochastic Geometry, (Springer Berlin Heidelberg), pp. 1-75.

Balagopalan, L., Barr, V.A., Kortum, R.L., Park, A.K., and Samelson, L.E. (2013). Cutting edge: cell surface linker for activation of $\mathrm{T}$ cells is recruited to microclusters and is active in signaling. J. Immunol. Baltim. Md 1950 190, 3849-3853.

Barreiro, O., Zamai, M., Yáñez-Mó, M., Tejera, E., López-Romero, P., Monk, P.N., Gratton, E., Caiolfa, V.R., and Sánchez-Madrid, F. (2008). Endothelial adhesion receptors are recruited to adherent leukocytes by inclusion in preformed tetraspanin nanoplatforms. J. Cell Biol. 183, 527-542.

Bastiani, M., Liu, L., Hill, M.M., Jedrychowski, M.P., Nixon, S.J., Lo, H.P., Abankwa, D., Luetterforst, R., Fernandez-Rojo, M., Breen, M.R., et al. (2009). MURC/Cavin-4 and cavin family members form tissue-specific caveolar complexes. J. Cell Biol. 185, 1259-1273.

Belardi, B., O’Donoghue, G.P., Smith, A.W., Groves, J.T., and Bertozzi, C.R. (2012). Investigating cell surface galectin-mediated cross-linking on glycoengineered cells. J. Am. Chem. Soc. 134, 9549-9552.

Betzig, E., and Chichester, R.J. (1993). Single molecules observed by near-field scanning optical microscopy. Science 262, 1422-1425.

Betzig, E., and Trautman, J.K. (1992). Near-field optics: microscopy, spectroscopy, and surface modification beyond the diffraction limit. Science 257, 189-195.

Betzig, E., Patterson, G.H., Sougrat, R., Lindwasser, O.W., Olenych, S., Bonifacino, J.S., Davidson, M.W., Lippincott-Schwartz, J., and Hess, H.F. (2006). Imaging intracellular fluorescent proteins at nanometer resolution. Science 313, 1642-1645.

Blom, H., RöNnlund, D., Scott, L., Spicarova, Z., Rantanen, V., Widengren, J., Aperia, A., and Brismar, H. (2012). Nearest neighbor analysis of dopamine D1 receptors and Na+-K+-ATPases in dendritic spines dissected by STED microscopy. Microsc. Res. Tech. 75, 220-228.

Van den Bogaart, G., Meyenberg, K., Risselada, H.J., Amin, H., Willig, K.I., Hubrich, B.E., Dier, M., Hell, S.W., Grubmüller, H., Diederichsen, U., et al. (2011). Membrane protein sequestering by ionic protein-lipid interactions. Nature 479, 552-555. 
Bolte, S., and Cordelières, F.P. (2006). A guided tour into subcellular colocalization analysis in light microscopy. J. Microsc. 224, 213-232.

Boscher, C., Dennis, J.W., and Nabi, I.R. (2011). Glycosylation, galectins and cellular signaling. Curr. Opin. Cell Biol. 23, 383-392.

Boucheix, C., and Rubinstein, E. (2001). Tetraspanins. Cell. Mol. Life Sci. CMLS 58, 1189-1205.

Brewer, C.F., Miceli, M.C., and Baum, L.G. (2002). Clusters, bundles, arrays and lattices: novel mechanisms for lectin-saccharide-mediated cellular interactions. Curr. Opin. Struct. Biol. 12, 616-623.

Brown, D.A., and Rose, J.K. (1992). Sorting of GPI-anchored proteins to glycolipid-enriched membrane subdomains during transport to the apical cell surface. Cell 68, 533-544.

Burt, J.E., Barber, G.M., and Rigby, D.L. (2009). Elementary Statistics for Geographers, Third Edition (Guilford Press).

Cardona, A., Saalfeld, S., Preibisch, S., Schmid, B., Cheng, A., Pulokas, J., Tomancak, P., and Hartenstein, V. (2010). An Integrated Micro- and Macroarchitectural Analysis of the Drosophila Brain by Computer-Assisted Serial Section Electron Microscopy. PLoS Biol. 8, e1000502.

Chaney, L.K., and Jacobson, B.S. (1983). Coating cells with colloidal silica for high yield isolation of plasma membrane sheets and identification of transmembrane proteins. J. Biol. Chem. 258, 10062 10072.

Chaudhary, N., Gomez, G.A., Howes, M.T., Lo, H.P., McMahon, K.-A., Rae, J.A., Schieber, N.L., Hill, M.M., Gaus, K., Yap, A.S., et al. (2014). Endocytic crosstalk: cavins, caveolins, and caveolae regulate clathrin-independent endocytosis. PLoS Biol. 12, e1001832.

Constals, A., Penn, A.C., Compans, B., Toulmé, E., Phillipat, A., Marais, S., Retailleau, N., Hafner, A.S., Coussen, F., Hosy, E., et al. (2015). Glutamate-Induced AMPA Receptor Desensitization Increases Their Mobility and Modulates Short-Term Plasticity through Unbinding from Stargazin. Neuron 85, 787-803.

Cox, S., Rosten, E., Monypenny, J., Jovanovic-Talisman, T., Burnette, D.T., Lippincott-Schwartz, J., Jones, G.E., and Heintzmann, R. (2012). Bayesian localization microscopy reveals nanoscale podosome dynamics. Nat. Methods 9, 195-200.

Cressie, A.C.N. (1993). Statistics for Spatial Data (Wiley and Sons).

Dertinger, T., Colyer, R., Iyer, G., Weiss, S., and Enderlein, J. (2009). Fast, background-free, 3D superresolution optical fluctuation imaging (SOFI). Proc. Natl. Acad. Sci. U. S. A. 106, 22287-22292.

Deschout, H., Shivanandan, A., Annibale, P., Scarselli, M., and Radenovic, A. (2014). Progress in quantitative single-molecule localization microscopy. Histochem. Cell Biol. 142, 5-17.

Diaz-Rohrer, B., Levental, K.R., and Levental, I. (2014). Rafting through traffic: Membrane domains in cellular logistics. Biochim. Biophys. Acta BBA - Biomembr. 1838, 3003-3013.

Diggle, P.J. (2003). Statistical Analysis of Spatial Point Patterns (London; New York: Hodder Education Publishers).

Dixon, P.M. (2002). Ripley's K function. In Encyclopedia of Environmetrics, (Abdel H. El-Shaarawi and Walter W. Piegorsch John Wiley \& Sons, Ltd, Chichester), pp. 1796-1803. 
Ehrig, J., Petrov, E.P., and Schwille, P. (2011). Near-Critical Fluctuations and Cytoskeleton-Assisted Phase Separation Lead to Subdiffusion in Cell Membranes. Biophys. J. 100, 80-89.

Ester, M., Kriegel, H., S, J., and Xu, X. (1996). A density-based algorithm for discovering clusters in large spatial databases with noise. (AAAI Press), pp. 226-231.

Feigenson, G.W. (2007). Phase boundaries and biological membranes. Annu. Rev. Biophys. Biomol. Struct. 36, 63-77.

Flors, C., Hotta, J., Uji-i, H., Dedecker, P., Ando, R., Mizuno, H., Miyawaki, A., and Hofkens, J. (2007). A Stroboscopic Approach for Fast Photoactivation-Localization Microscopy with Dronpa Mutants. J. Am. Chem. Soc. 129, 13970-13977.

Fölling, J., Bossi, M., Bock, H., Medda, R., Wurm, C.A., Hein, B., Jakobs, S., Eggeling, C., and Hell, S.W. (2008). Fluorescence nanoscopy by ground-state depletion and single-molecule return. Nat. Methods 5, 943-945.

Friedl, P., den Boer, A.T., and Gunzer, M. (2005). Tuning immune responses: diversity and adaptation of the immunological synapse. Nat. Rev. Immunol. 5, 532-545.

Fujiwara, T., Ritchie, K., Murakoshi, H., Jacobson, K., and Kusumi, A. (2002). Phospholipids undergo hop diffusion in compartmentalized cell membrane. J. Cell Biol. 157, 1071-1082.

Gambin, Y., Ariotti, N., McMahon, K.-A., Bastiani, M., Sierecki, E., Kovtun, O., Polinkovsky, M.E., Magenau, A., Jung, W., Okano, S., et al. (2014). Single-molecule analysis reveals self assembly and nanoscale segregation of two distinct cavin subcomplexes on caveolae. eLife 3, e01434.

García-Cardeña, G., Fan, R., Stern, D.F., Liu, J., and Sessa, W.C. (1996). Endothelial nitric oxide synthase is regulated by tyrosine phosphorylation and interacts with caveolin-1. J. Biol. Chem. 271, $27237-27240$

Garcia-Parajo, M.F., Cambi, A., Torreno-Pina, J.A., Thompson, N., and Jacobson, K. (2014). Nanoclustering as a dominant feature of plasma membrane organization. J. Cell Sci. 127, 4995-5005.

Garner, O.B., and Baum, L.G. (2008). Galectin-glycan lattices regulate cell-surface glycoprotein organization and signalling. Biochem. Soc. Trans. 36, 1472-1477.

Geisler, C., Schönle, A., Middendorff, C. von, Bock, H., Eggeling, C., Egner, A., and Hell, S.W. (2007). Resolution of $\lambda / 10$ in fluorescence microscopy using fast single molecule photo-switching. Appl. Phys. A $88,223-226$.

Getis, A., and Ord, J.K. (1992). The Analysis of Spatial Association by Use of Distance Statistics. Geogr. Anal. 24, 189-206.

Godin, A.G., Costantino, S., Lorenzo, L.-E., Swift, J.L., Sergeev, M., Ribeiro-da-Silva, A., Koninck, Y.D., and Wiseman, P.W. (2011). Revealing protein oligomerization and densities in situ using spatial intensity distribution analysis. Proc. Natl. Acad. Sci. 108, 7010-7015.

Gong, W., Si, K., Chen, N., and Sheppard, C.J.R. (2010). Focal modulation microscopy with annular apertures: a numerical study. J. Biophotonics 3, 476-484.

Gorter, E., and Grendel, F. (1925). On bimolecular layers of lipoids on the chromocytes of the blood. J. Exp. Med. 41, 439-443. 
Gudheti, M.V., Curthoys, N.M., Gould, T.J., Kim, D., Gunewardene, M.S., Gabor, K.A., Gosse, J.A., Kim, C.H., Zimmerberg, J., and Hess, S.T. (2013). Actin Mediates the Nanoscale Membrane Organization of the Clustered Membrane Protein Influenza Hemagglutinin. Biophys. J. 104, 2182-2192.

Gustafsson, M.G. (2000). Surpassing the lateral resolution limit by a factor of two using structured illumination microscopy. J. Microsc. 198, 82-87.

Gustafsson, M.G.L. (2005). Nonlinear structured-illumination microscopy: wide-field fluorescence imaging with theoretically unlimited resolution. Proc. Natl. Acad. Sci. U. S. A. 102, 13081-13086.

Hamel, V., Guichard, P., Fournier, M., Guiet, R., Flückiger, I., Seitz, A., and Gönczy, P. (2014). Correlative multicolor 3D SIM and STORM microscopy. Biomed. Opt. Express 5, 3326-3336.

Hansen, C.G., Bright, N.A., Howard, G., and Nichols, B.J. (2009). SDPR induces membrane curvature and functions in the formation of caveolae. Nat. Cell Biol. 11, 807-814.

Hansen, C.G., Howard, G., and Nichols, B.J. (2011). Pacsin 2 is recruited to caveolae and functions in caveolar biogenesis. J. Cell Sci. 124, 2777-2785.

Haque, U., Overgaard, H.J., Clements, A.C.A., Norris, D.E., Islam, N., Karim, J., Roy, S., Haque, W., Kabir, M., Smith, D.L., et al. (2014). Malaria burden and control in Bangladesh and prospects for elimination: an epidemiological and economic assessment. Lancet Glob. Health 2, e98-e105.

Hayer, A., Stoeber, M., Bissig, C., and Helenius, A. (2010). Biogenesis of Caveolae: Stepwise Assembly of Large Caveolin and Cavin Complexes. Traffic 11, 361-382.

Heilemann, M., van de Linde, S., Schüttpelz, M., Kasper, R., Seefeldt, B., Mukherjee, A., Tinnefeld, P., and Sauer, M. (2008). Subdiffraction-Resolution Fluorescence Imaging with Conventional Fluorescent Probes. Angew. Chem. Int. Ed. 47, 6172-6176.

Heilemann, M., van de Linde, S., Mukherjee, A., and Sauer, M. (2009). Super-resolution imaging with small organic fluorophores. Angew. Chem. Int. Ed Engl. 48, 6903-6908.

Heintzmann, R. (2003). Saturated patterned excitation microscopy with two-dimensional excitation patterns. Micron Oxf. Engl. 1993 34, 283-291.

Heintzmann, R., and Cremer, C.G. (1999). Laterally modulated excitation microscopy: improvement of resolution by using a diffraction grating. pp. 185-196.

Heintzmann, R., Jovin, T.M., and Cremer, C. (2002). Saturated patterned excitation microscopy--a concept for optical resolution improvement. J. Opt. Soc. Am. A Opt. Image Sci. Vis. 19, 1599-1609.

Hell, S.W., and Kroug, M. (1995). Ground-state-depletion fluorscence microscopy: A concept for breaking the diffraction resolution limit. Appl. Phys. B 60, 495-497.

Hell, S.W., and Wichmann, J. (1994). Breaking the diffraction resolution limit by stimulated emission: stimulated-emission-depletion fluorescence microscopy. Opt. Lett. 19, 780-782.

Helmuth, J.A., Paul, G., and Sbalzarini, I.F. (2010). Beyond co-localization: inferring spatial interactions between sub-cellular structures from microscopy images. BMC Bioinformatics 11, 1-12.

Hemler, M.E. (2003). Tetraspanin proteins mediate cellular penetration, invasion, and fusion events and define a novel type of membrane microdomain. Annu. Rev. Cell Dev. Biol. 19, 397-422.

Hemler, M.E. (2005). Tetraspanin functions and associated microdomains. Nat. Rev. Mol. Cell Biol. 6, 801-811. 
Henriques, R., Lelek, M., Fornasiero, E.F., Valtorta, F., Zimmer, C., and Mhlanga, M.M. (2010). QuickPALM: 3D real-time photoactivation nanoscopy image processing in ImageJ. Nat. Methods 7, 339-340.

Hess, S.T., Girirajan, T.P.K., and Mason, M.D. (2006). Ultra-High Resolution Imaging by Fluorescence Photoactivation Localization Microscopy. Biophys. J. 91, 4258-4272.

Honigmann, A., van den Bogaart, G., Iraheta, E., Risselada, H.J., Milovanovic, D., Mueller, V., Müllar, S., Diederichsen, U., Fasshauer, D., Grubmüller, H., et al. (2013). Phosphatidylinositol 4,5-bisphosphate clusters act as molecular beacons for vesicle recruitment. Nat. Struct. Mol. Biol. 20, 679-686.

Hoze, N., Nair, D., Hosy, E., Sieben, C., Manley, S., Herrmann, A., Sibarita, J.-B., Choquet, D., and Holcman, D. (2012). Heterogeneity of AMPA receptor trafficking and molecular interactions revealed by superresolution analysis of live cell imaging. Proc. Natl. Acad. Sci. 109, 17052-17057.

Ipsen, J.H., Karlström, G., Mouritsen, O.G., Wennerström, H., and Zuckermann, M.J. (1987). Phase equilibria in the phosphatidylcholine-cholesterol system. Biochim. Biophys. Acta 905, 162-172.

Itano, M.S., Steinhauer, C., Schmied, J.J., Forthmann, C., Liu, P., Neumann, A.K., Thompson, N.L., Tinnefeld, P., and Jacobson, K. (2012). Super-resolution imaging of C-type lectin and influenza hemagglutinin nanodomains on plasma membranes using blink microscopy. Biophys. J. 102, 15341542.

James, D.J., Khodthong, C., Kowalchyk, J.A., and Martin, T.F.J. (2008). Phosphatidylinositol 4,5bisphosphate regulates SNARE-dependent membrane fusion. J. Cell Biol. 182, 355-366.

Kellner, R.R., Baier, C.J., Willig, K.I., Hell, S.W., and Barrantes, F.J. (2007). Nanoscale organization of nicotinic acetylcholine receptors revealed by stimulated emission depletion microscopy. Neuroscience 144, 135-143.

Khuong, T.M., Habets, R.L.P., Kuenen, S., Witkowska, A., Kasprowicz, J., Swerts, J., Jahn, R., van den Bogaart, G., and Verstreken, P. (2013). Synaptic PI(3,4,5)P3 Is Required for Syntaxin1A Clustering and Neurotransmitter Release. Neuron 77, 1097-1108.

Kiskowski, M.A., Hancock, J.F., and Kenworthy, A.K. (2009). On the Use of Ripley's K-Function and Its Derivatives to Analyze Domain Size. Biophys. J. 97, 1095-1103.

Klein, T., Proppert, S., and Sauer, M. (2014). Eight years of single-molecule localization microscopy. Histochem. Cell Biol. 141, 561-575.

Kusumi, A., and Sako, Y. (1996). Cell surface organization by the membrane skeleton. Curr. Opin. Cell Biol. 8, 566-574.

Kusumi, A., Sako, Y., and Yamamoto, M. (1993). Confined lateral diffusion of membrane receptors as studied by single particle tracking (nanovid microscopy). Effects of calcium-induced differentiation in cultured epithelial cells. Biophys. J. 65, 2021-2040.

Kusumi, A., Suzuki, K.G.N., Kasai, R.S., Ritchie, K., and Fujiwara, T.K. (2011). Hierarchical mesoscale domain organization of the plasma membrane. Trends Biochem. Sci. 36, 604-615.

Kusumi, A., Fujiwara, T.K., Morone, N., Yoshida, K.J., Chadda, R., Xie, M., Kasai, R.S., and Suzuki, K.G.N. (2012). Membrane mechanisms for signal transduction: The coupling of the meso-scale raft domains to membrane-skeleton-induced compartments and dynamic protein complexes. Semin. Cell Dev. Biol. 23, 126-144. 
Kusumi, A., Tsunoyama, T.A., Hirosawa, K.M., Kasai, R.S., and Fujiwara, T.K. (2014). Tracking single molecules at work in living cells. Nat. Chem. Biol. 10, 524-532.

Lagache, T., Lang, G., Sauvonnet, N., and Olivo-Marin, J.-C. (2013). Analysis of the spatial organization of molecules with robust statistics. PloS One 8, e80914.

Lakshminarayan, R., Wunder, C., Becken, U., Howes, M.T., Benzing, C., Arumugam, S., Sales, S., Ariotti, N., Chambon, V., Lamaze, C., et al. (2014). Galectin-3 drives glycosphingolipid-dependent biogenesis of clathrin-independent carriers. Nat. Cell Biol. 16, 592-603.

Lehmann, M., Rocha, S., Mangeat, B., Blanchet, F., Uji-i, H., Hofkens, J., and Piguet, V. (2011). Quantitative Multicolor Super-Resolution Microscopy Reveals Tetherin HIV-1 Interaction. PLoS Pathog 7, e1002456.

Levental, I., Lingwood, D., Grzybek, M., Coskun, Ü., and Simons, K. (2010). Palmitoylation regulates raft affinity for the majority of integral raft proteins. Proc. Natl. Acad. Sci. U. S. A. 107, 22050-22054.

Li, R., and Gundersen, G.G. (2008). Beyond polymer polarity: how the cytoskeleton builds a polarized cell. Nat. Rev. Mol. Cell Biol. 9, 860-873.

Lidke, K., Rieger, B., Jovin, T., and Heintzmann, R. (2005). Superresolution by localization of quantum dots using blinking statistics. Opt. Express 13, 7052-7062.

Lillemeier, B.F., Mörtelmaier, M.A., Forstner, M.B., Huppa, J.B., Groves, J.T., and Davis, M.M. (2010). TCR and Lat are expressed on separate protein islands on T cell membranes and concatenate during activation. Nat. Immunol. 11, 90-96.

Liu, L., Brown, D., McKee, M., Lebrasseur, N.K., Yang, D., Albrecht, K.H., Ravid, K., and Pilch, P.F. (2008). Deletion of Cavin/PTRF causes global loss of caveolae, dyslipidemia, and glucose intolerance. Cell Metab. 8, 310-317.

London, E. (2002). Insights into lipid raft structure and formation from experiments in model membranes. Curr. Opin. Struct. Biol. 12, 480-486.

Ludwig, A., Howard, G., Mendoza-Topaz, C., Deerinck, T., Mackey, M., Sandin, S., Ellisman, M.H., and Nichols, B.J. (2013). Molecular Composition and Ultrastructure of the Caveolar Coat Complex. PLoS Biol 11, e1001640.

MacGillavry, H.D., Song, Y., Raghavachari, S., and Blanpied, T.A. (2013). Nanoscale Scaffolding Domains within the Postsynaptic Density Concentrate Synaptic AMPA Receptors. Neuron 78, 615-622.

Malissen, B., Grégoire, C., Malissen, M., and Roncagalli, R. (2014). Integrative biology of T cell activation. Nat. Immunol. 15, 790-797.

Mandula, O., Šestak, I.Š., Heintzmann, R., and Williams, C.K.I. (2014). Localisation microscopy with quantum dots using non-negative matrix factorisation. Opt. Express 22, 24594-24605.

Marin, R., Rojo, J.A., Fabelo, N., Fernandez, C.E., and Diaz, M. (2013). Lipid raft disarrangement as a result of neuropathological progresses: a novel strategy for early diagnosis? Neuroscience 245, 26-39.

Mattfeldt, T. (2005). Explorative statistical analysis of planar point processes in microscopy. J. Microsc. 220, 131-139.

McMahon, K.-A., Zajicek, H., Li, W.-P., Peyton, M.J., Minna, J.D., Hernandez, V.J., Luby-Phelps, K., and Anderson, R.G.W. (2009). SRBC/cavin-3 is a caveolin adapter protein that regulates caveolae function. EMBO J. 28, 1001-1015. 
Meister, M., and Tikkanen, R. (2014). Endocytic trafficking of membrane-bound cargo: a flotillin point of view. Membranes 4, 356-371.

Milovanovic, D., and Jahn, R. (2015). Organization and dynamics of SNARE proteins in the presynaptic membrane. Front. Physiol. 6, 89.

Mollinedo, F., and Gajate, C. (2015). Lipid rafts as major platforms for signaling regulation in cancer. Adv. Biol. Regul. 57, 130-146.

Morén, B., Shah, C., Howes, M.T., Schieber, N.L., McMahon, H.T., Parton, R.G., Daumke, O., and Lundmark, R. (2012). EHD2 regulates caveolar dynamics via ATP-driven targeting and oligomerization. Mol. Biol. Cell 23, 1316-1329.

Mueller, N.S., Wedlich-Söldner, R., and Spira, F. (2012). From mosaic to patchwork: Matching lipids and proteins in membrane organization. Mol. Membr. Biol. 29, 186-196.

Munck, S., Miskiewicz, K., Sannerud, R., Menchon, S.A., Jose, L., Heintzmann, R., Verstreken, P., and Annaert, W. (2012). Sub-diffraction imaging on standard microscopes through photobleaching microscopy with non-linear processing. J. Cell Sci. 125, 2257-2266.

Nair, D., Hosy, E., Petersen, J.D., Constals, A., Giannone, G., Choquet, D., and Sibarita, J.-B. (2013). Super-Resolution Imaging Reveals That AMPA Receptors Inside Synapses Are Dynamically Organized in Nanodomains Regulated by PSD95. J. Neurosci. 33, 13204-13224.

Nassoy, P., and Lamaze, C. (2012). Stressing caveolae new role in cell mechanics. Trends Cell Biol. 22, $381-389$.

Nawaz, S., Heindl, A., Koelble, K., and Yuan, Y. (2015). Beyond immune density: critical role of spatial heterogeneity in estrogen receptor-negative breast cancer. Mod. Pathol. Off. J. U. S. Can. Acad. Pathol. Inc.

Nicolson, G.L. (2014). The Fluid-Mosaic Model of Membrane Structure: still relevant to understanding the structure, function and dynamics of biological membranes after more than 40 years. Biochim. Biophys. Acta 1838, 1451-1466.

Nieuwenhuizen, R.P.J., Lidke, K.A., Bates, M., Puig, D.L., Grünwald, D., Stallinga, S., and Rieger, B. (2013). Measuring image resolution in optical nanoscopy. Nat. Methods 10, 557-562.

Notelaers, K., Rocha, S., Paesen, R., Swinnen, N., Vangindertael, J., Meier, J.C., Rigo, J.-M., Ameloot, M., and Hofkens, J. (2014). Membrane distribution of the glycine receptor $\alpha 3$ studied by optical superresolution microscopy. Histochem. Cell Biol. 142, 79-90.

Okabe, S. (2007). Molecular anatomy of the postsynaptic density. Mol. Cell. Neurosci. 34, 503-518.

Bar-On, D., Wolter, S., van de Linde, S., Heilemann, M., Nudelman, G., Nachliel, E., Gutman, M., Sauer, M., and Ashery, U. (2012). Super-resolution imaging reveals the internal architecture of nanosized syntaxin clusters. J. Biol. Chem. 287, 27158-27167.

Otto, G.P., and Nichols, B.J. (2011). The roles of flotillin microdomains--endocytosis and beyond. J. Cell Sci. 124, 3933-3940.

Owen, D.M., Gaus, K., Magee, A.I., and Cebecauer, M. (2010). Dynamic organization of lymphocyte plasma membrane: lessons from advanced imaging methods. Immunology $131,1-8$.

Palade, G.E. (1953). Fine structure of blood capillaries. Journal of Applied Physics. J. Appl. Phys. 24. 
Parton, R.G., and del Pozo, M.A. (2013). Caveolae as plasma membrane sensors, protectors and organizers. Nat. Rev. Mol. Cell Biol. 14, 98-112.

Parton, R.G., and Simons, K. (2007). The multiple faces of caveolae. Nat. Rev. Mol. Cell Biol. 8, 185194.

Pelkmans, L., Bürli, T., Zerial, M., and Helenius, A. (2004). Caveolin-stabilized membrane domains as multifunctional transport and sorting devices in endocytic membrane traffic. Cell 118, 767-780.

Pertsinidis, A., Mukherjee, K., Sharma, M., Pang, Z.P., Park, S.R., Zhang, Y., Brunger, A.T., Südhof, T.C., and Chu, S. (2013). Ultrahigh-resolution imaging reveals formation of neuronal SNARE/Munc18 complexes in situ. Proc. Natl. Acad. Sci. 110, E2812-E2820.

Peters, K.R., Carley, W.W., and Palade, G.E. (1985). Endothelial plasmalemmal vesicles have a characteristic striped bipolar surface structure. J. Cell Biol. 101, 2233-2238.

Pike, L.J. (2006). Rafts defined: a report on the Keystone symposium on lipid rafts and cell function. J. Lipid Res. 47, 1597-1598.

Prior, I.A., Muncke, C., Parton, R.G., and Hancock, J.F. (2003). Direct visualization of Ras proteins in spatially distinct cell surface microdomains. J. Cell Biol. 160, 165-170.

Prodanov, D., Nagelkerke, N., and Marani, E. (2007). Spatial clustering analysis in neuroanatomy: applications of different approaches to motor nerve fiber distribution. J. Neurosci. Methods 160, 93108.

Rabinovich, G.A., Toscano, M.A., Jackson, S.S., and Vasta, G.R. (2007). Functions of cell surface galectin-glycoprotein lattices. Curr. Opin. Struct. Biol. 17, 513-520.

Ramadoss, J., Pastore, M.B., and Magness, R.R. (2013). Endothelial Caveolar Subcellular Domain Regulation of Endothelial Nitric Oxide Synthase. Clin. Exp. Pharmacol. Physiol. 40, 753-764.

Rayleigh, Lord (1903). On the Theory of Optical Images, with special reference to the Microscope. J. R. Microsc. Soc. 23, 474-482.

Ries, J., Kaplan, C., Platonova, E., Eghlidi, H., and Ewers, H. (2012). A simple, versatile method for GFP-based super-resolution microscopy via nanobodies. Nat. Methods 9, 582-584.

Ripley, B.D. (1977). Modelling Spatial Patterns. J. R. Stat. Soc. B 39, 172-212.

Ristanović, Z., Kerssens, M.M., Kubarev, A.V., Hendriks, F.C., Dedecker, P., Hofkens, J., Roeffaers, M.B.J., and Weckhuysen, B.M. (2015). High-resolution single-molecule fluorescence imaging of zeolite aggregates within real-life fluid catalytic cracking particles. Angew. Chem. Int. Ed Engl. 54, 18361840.

Ritchie, K., Iino, R., Fujiwara, T., Murase, K., and Kusumi, A. (2003). The fence and picket structure of the plasma membrane of live cells as revealed by single molecule techniques (Review). Mol. Membr. Biol. 20, 13-18.

Rossy, J., Williamson, D.J., Benzing, C., and Gaus, K. (2012). The integration of signaling and the spatial organization of the T cell synapse. Immunol. Mem. 3, 352.

Rothberg, K.G., Heuser, J.E., Donzell, W.C., Ying, Y.-S., Glenney, J.R., and Anderson, R.G.W. (1992). Caveolin, a protein component of caveolae membrane coats. Cell 68, 673-682. 
Rust, M.J., Bates, M., and Zhuang, X. (2006). Sub-diffraction-limit imaging by stochastic optical reconstruction microscopy (STORM). Nat. Methods 3, 793-796.

Saka, S.K., Honigmann, A., Eggeling, C., Hell, S.W., Lang, T., and Rizzoli, S.O. (2014). Multi-protein assemblies underlie the mesoscale organization of the plasma membrane. Nat. Commun. 5.

Sauer, M. (2013). Localization microscopy coming of age: from concepts to biological impact. J. Cell Sci. $126,3505-3513$.

Scarselli, M., Annibale, P., and Radenovic, A. (2012). Cell type-specific $\beta 2$-adrenergic receptor clusters identified using photoactivated localization microscopy are not lipid raft related, but depend on actin cytoskeleton integrity. J. Biol. Chem. 287, 16768-16780.

Scherer, P.E., Tang, Z., Chun, M., Sargiacomo, M., Lodish, H.F., and Lisanti, M.P. (1995). Caveolin Isoforms Differ in Their N-terminal Protein Sequence and Subcellular Distribution. Identification and epitope mapping of an isoform-specific monoclonal antibody probe. J. Biol. Chem. 270, 16395-16401.

Scherer, P.E., Okamoto, T., Chun, M., Nishimoto, I., Lodish, H.F., and Lisanti, M.P. (1996). Identification, sequence, and expression of caveolin-2 defines a caveolin gene family. Proc. Natl. Acad. Sci. U. S. A. 93, 131-135.

Schermelleh, L., Heintzmann, R., and Leonhardt, H. (2010). A guide to super-resolution fluorescence microscopy. J. Cell Biol. 190, 165-175.

Schindelin, J., Arganda-Carreras, I., Frise, E., Kaynig, V., Longair, M., Pietzsch, T., Preibisch, S., Rueden, C., Saalfeld, S., Schmid, B., et al. (2012). Fiji: an open-source platform for biological-image analysis. Nat. Methods 9, 676-682.

Schroeder, R., London, E., and Brown, D. (1994). Interactions between saturated acyl chains confer detergent resistance on lipids and glycosylphosphatidylinositol (GPI)-anchored proteins: GPI-anchored proteins in liposomes and cells show similar behavior. Proc. Natl. Acad. Sci. U. S. A. 91, 12130-12134.

Schulte, T., Paschke, K.A., Laessing, U., Lottspeich, F., and Stuermer, C.A. (1997). Reggie-1 and reggie-2, two cell surface proteins expressed by retinal ganglion cells during axon regeneration. Dev. Camb. Engl. 124, 577-587.

Seigneuret, M. (2006). Complete predicted three-dimensional structure of the facilitator transmembrane protein and hepatitis $\mathrm{C}$ virus receptor CD81: conserved and variable structural domains in the tetraspanin superfamily. Biophys. J. 90, 212-227.

Sengupta, P., and Lippincott-Schwartz, J. (2012). Quantitative analysis of photoactivated localization microscopy (PALM) datasets using pair-correlation analysis. BioEssays News Rev. Mol. Cell. Dev. Biol. 34, 396-405.

Sengupta, P., Jovanovic-Talisman, T., Skoko, D., Renz, M., Veatch, S.L., and Lippincott-Schwartz, J. (2011). Probing protein heterogeneity in the plasma membrane using PALM and pair correlation analysis. Nat. Methods 8, 969-975.

Sengupta, P., Jovanovic-Talisman, T., and Lippincott-Schwartz, J. (2013). Quantifying spatial organization in point-localization superresolution images using pair correlation analysis. Nat. Protoc. 8 , $345-354$.

Senju, Y., Itoh, Y., Takano, K., Hamada, S., and Suetsugu, S. (2011). Essential role of PACSIN2/syndapin-II in caveolae membrane sculpting. J. Cell Sci. 124, 2032-2040. 
Sezgin, E., Gutmann, T., Buhl, T., Dirkx, R., Grzybek, M., Coskun, Ü., Solimena, M., Simons, K., Levental, I., and Schwille, P. (2015). Adaptive Lipid Packing and Bioactivity in Membrane Domains. PLOS ONE 10, e0123930.

Sharonov, A., and Hochstrasser, R.M. (2006). Wide-field subdiffraction imaging by accumulated binding of diffusing probes. Proc. Natl. Acad. Sci. 103, 18911-18916.

Sherman, E., Barr, V., Manley, S., Patterson, G., Balagopalan, L., Akpan, I., Regan, C.K., Merrill, R.K., Sommers, C.L., Lippincott-Schwartz, J., et al. (2011). Functional Nanoscale Organization of Signaling Molecules Downstream of the T Cell Antigen Receptor. Immunity 35, 705-720.

Shivanandan, A., Radenovic, A., and Sbalzarini, I.F. (2013). MosaicIA: an ImageJ/Fiji plugin for spatial pattern and interaction analysis. BMC Bioinformatics 14, 349.

Shivanandan, A., Unnikrishnan, J., and Radenovic, A. (2015). Accounting for Limited Detection Efficiency and Localization Precision in Cluster Analysis in Single Molecule Localization Microscopy. PLoS ONE 10, e0118767.

Sieber, J.J., Willig, K.I., Kutzner, C., Gerding-Reimers, C., Harke, B., Donnert, G., Rammner, B., Eggeling, C., Hell, S.W., Grubmüller, H., et al. (2007). Anatomy and Dynamics of a Supramolecular Membrane Protein Cluster. Science 317, 1072-1076.

Simons, K., and Ikonen, E. (1997). Functional rafts in cell membranes. Nature 387, 569-572.

Simons, K., and Van Meer, G. (1988). Lipid sorting in epithelial cells. Biochemistry (Mosc.) 27, 61976202.

Simons, K., and Sampaio, J.L. (2011). Membrane Organization and Lipid Rafts. Cold Spring Harb. Perspect. Biol. 3.

Simons, K., and Toomre, D. (2000). Lipid rafts and signal transduction. Nat. Rev. Mol. Cell Biol. 1, 3139.

Singer, S.J., and Nicolson, G.L. (1972). The fluid mosaic model of the structure of cell membranes. Science $175,720-731$.

Smith-Garvin, J.E., Koretzky, G.A., and Jordan, M.S. (2009). T Cell Activation. Annu. Rev. Immunol. 27, 591-619.

Solis, G.P., Hoegg, M., Munderloh, C., Schrock, Y., Malaga-Trillo, E., Rivera-Milla, E., and Stuermer, C.A.O. (2007). Reggie/flotillin proteins are organized into stable tetramers in membrane microdomains. Biochem. J. 403, 313-322.

Sparrow, C.M. (1916). On Spectroscopic Resolving Power. Astrophys. J. 44, 76.

Stipp, C.S., Kolesnikova, T.V., and Hemler, M.E. (2003). Functional domains in tetraspanin proteins. Trends Biochem. Sci. 28, 106-112.

Stoeber, M., Stoeck, I.K., Hänni, C., Bleck, C.K.E., Balistreri, G., and Helenius, A. (2012). Oligomers of the ATPase EHD2 confine caveolae to the plasma membrane through association with actin. EMBO J. 31, 2350-2364.

Südhof, T.C. (2012). The Presynaptic Active Zone. Neuron 75, 11-25. 
Tang, Z., Scherer, P.E., Okamoto, T., Song, K., Chu, C., Kohtz, D.S., Nishimoto, I., Lodish, H.F., and Lisanti, M.P. (1996). Molecular Cloning of Caveolin-3, a Novel Member of the Caveolin Gene Family Expressed Predominantly in Muscle. J. Biol. Chem. 271, 2255-2261.

Termini, C.M., Cotter, M.L., Marjon, K.D., Buranda, T., Lidke, K.A., and Gillette, J.M. (2014). The membrane scaffold CD 82 regulates cell adhesion by altering $\alpha 4$ integrin stability and molecular density. Mol. Biol. Cell 25, 1560-1573.

Tobin, S.J., Cacao, E.E., Hong, D.W.W., Terenius, L., Vukojevic, V., and Jovanovic-Talisman, T. (2014). Nanoscale effects of ethanol and naltrexone on protein organization in the plasma membrane studied by photoactivated localization microscopy (PALM). PloS One 9, e87225.

Torreno-Pina, J.A., Castro, B.M., Manzo, C., Buschow, S.I., Cambi, A., and Garcia-Parajo, M.F. (2014). Enhanced receptor-clathrin interactions induced by $\mathrm{N}$-glycan-mediated membrane micropatterning. Proc. Natl. Acad. Sci. 111, 11037-11042.

Truan, Z., Tarancón Díez, L., Bönsch, C., Malkusch, S., Endesfelder, U., Munteanu, M., Hartley, O., Heilemann, M., and Fürstenberg, A. (2013). Quantitative morphological analysis of arrestin2 clustering upon G protein-coupled receptor stimulation by super-resolution microscopy. J. Struct. Biol. 184, 329334.

Veatch, S.L., Soubias, O., Keller, S.L., and Gawrisch, K. (2007). Critical fluctuations in domain-forming lipid mixtures. Proc. Natl. Acad. Sci. 104, 17650-17655.

Veatch, S.L., Machta, B.B., Shelby, S.A., Chiang, E.N., Holowka, D.A., and Baird, B.A. (2012). Correlation Functions Quantify Super-Resolution Images and Estimate Apparent Clustering Due to Over-Counting. PLoS ONE 7.

Wiegand, T., and Moloney, K.A. (2013). Handbook of Spatial Point-Pattern Analysis in Ecology (CRC Press).

Williamson, D.J., Owen, D.M., Rossy, J., Magenau, A., Wehrmann, M., Gooding, J.J., and Gaus, K. (2011). Pre-existing clusters of the adaptor Lat do not participate in early T cell signaling events. Nat. Immunol. 12, 655-662.

Wright, M.D., and Tomlinson, M.G. (1994). The ins and outs of the transmembrane 4 superfamily. Immunol. Today 15, 588-594.

Xie, J., Tato, C.M., and Davis, M.M. (2013). How the immune system talks to itself: the varied role of synapses. Immunol. Rev. 251, 65-79.

Yamada, E. (1955). The fine structure of the gall bladder epithelium of the mouse. J. Biophys. Biochem. Cytol. 1, 445-458.

Yáñez-Mó, M., Barreiro, O., Gordon-Alonso, M., Sala-Valdés, M., and Sánchez-Madrid, F. (2009). Tetraspanin-enriched microdomains: a functional unit in cell plasma membranes. Trends Cell Biol. 19, 434-446.

Zhang, J., Leiderman, K., Pfeiffer, J.R., Wilson, B.S., Oliver, J.M., and Steinberg, S.L. (2006). Characterizing the topography of membrane receptors and signaling molecules from spatial patterns obtained using nanometer-scale electron-dense probes and electron microscopy. Micron 37, 14-34.

Zhou, Y., and Hancock, J.F. (2015). Ras nanoclusters: Versatile lipid-based signaling platforms. Biochim. Biophys. Acta BBA - Mol. Cell Res. 1853, 841-849. 
Zhou, Y., Liang, H., Rodkey, T., Ariotti, N., Parton, R.G., and Hancock, J.F. (2014). Signal integration by lipid-mediated spatial cross talk between Ras nanoclusters. Mol. Cell. Biol. 34, 862-876. 